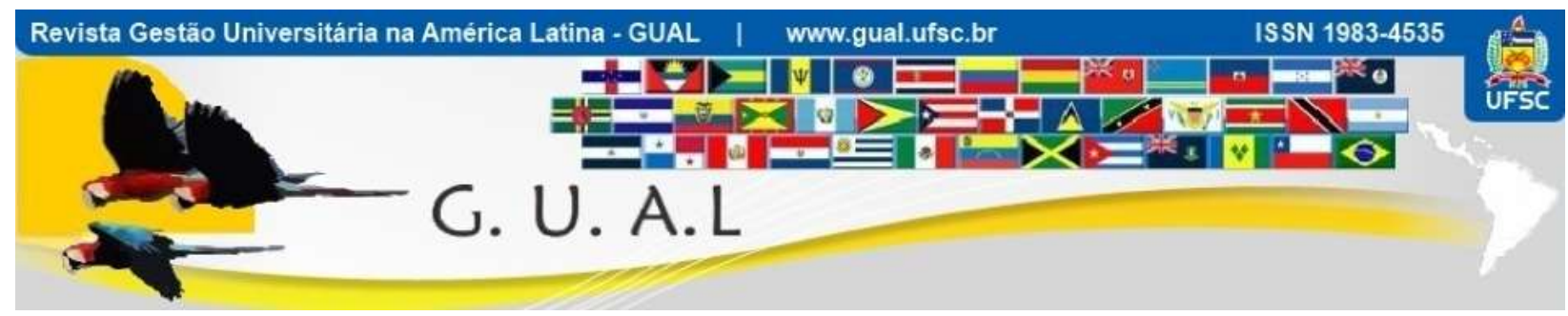

DOI: https://doi.org/10.5007/1983-4535.2021.e75780

\title{
CONHECIMENTOS SOBRE ESTRATÉGIAS DE ENSINO ATIVAS: REVELAÇÕES E CONSTATAÇÕES NO CORPO DOCENTE DE UM CURSO DE CONTÁBEIS EM UMA INSTITUIÇÃO DE ENSINO SUPERIOR BRASILEIRA
}

\section{KNOWLEDGE ABOUT ACTIVE TEACHING STRATEGIES: REVELATIONS AND FINDINGS IN THE FACULTY OF AN ACCOUNTING COURSE AT A BRAZILIAN HIGHER EDUCATION INSTITUTION}

Bruna Karla dos Santos, Bacharel
https://orcid.org/0000-0002-9402-9378
brunads.karla@gmail.com
Universidade Federal da Paraíba | Departamento de Ciências Sociais Aplicadas
João Pessoa | Paraíba | Brasil
Thales Batista de Lima, Doutor
http://orcid.org/0000-0002-2338-0451
thalesufpb@gmail.com
Universidade Federal da Paraíba | Departamento de Ciências Sociais Aplicadas
João Pessoa $\mid$ Paraíba $\mid$ Brasil

Recebido em 18/julho/2020

Aprovado em 03/fevereiro/2021

Publicado em 01/maio/2021

Sistema de Avaliação: Double Blind Review 


\title{
CONHECIMENTOS SOBRE ESTRATÉGIAS DE ENSINO ATIVAS: REVELAÇÕES E CONSTATAÇÕES \\ NO CORPO DOCENTE DE UM CURSO DE CONTÁBEIS EM UMA INSTITUIÇÃO DE ENSINO \\ SUPERIOR BRASILEIRA \\ DOI: https://doi.org/10.5007/1983-4535.2021.e75780
}

\section{RESUMO}

O estudo objetiva analisar a percepção dos docentes do curso de ciências contábeis do campus IV/UFPB/Brasil em relação à utilização das estratégias de ensino ativas. É de abordagem quantitativa, sendo realizado um questionário estruturado aplicado virtualmente e analisado por meio da estatística descritiva. Assim, os resultados demonstram que os professores pesquisados utilizam parcialmente as estratégias de ensino ativas como atividades e avaliações em sala de aula e enfatizam a necessidade de aperfeiçoamento de suas práticas docentes. O estudo revela que há dificuldades e desafios enfrentados pelos docentes respondentes do referido curso, em que se destacam a imaturidade e desinteresse de estudantes nas atividades realizadas ou pretendidas. Constata-se que aspectos como a experiência profissional dos professores e a adequada elaboração do plano de curso são fundamentais para alavancar a qualidade do ensino ofertada aos alunos, incentivando a postura ativa deles no aprendizado. Conclui-se que é indispensável para o curso estudado a busca por inovações em dinamizar o processo de ensino-aprendizagem por meio da divulgação dos conhecimentos das estratégias de ensino ativas entre o corpo docente para sua melhor qualificação profissional enquanto mediador no processo formativo dos contadores.

Palavras-chave: Estratégias de ensino ativas. Contabilidade. Docente.

\begin{abstract}
The study aims to analyze the perception of professors of the accounting science course on campus IV/UFPB /Brazil in relation to the use of active teaching strategies. It has a quantitative approach, with a structured questionnaire applied virtually and analyzed using descriptive statistics. Thus, the results show that the teachers surveyed partially use active teaching strategies such as classroom activities and assessments and emphasize the need to improve their teaching practices. The study reveals that there are difficulties and challenges faced by the teachers who responded to the referred course, in which the immaturity and lack of interest of students in the activities carried out or intended stand out. It appears that aspects such as the teachers' professional experience and the adequate preparation of the course plan are fundamental to leverage the quality of teaching offered to students, encouraging their active posture in learning. We conclude that it is indispensable for the studied course the search for innovations in dynamizing the teaching-learning process through the dissemination of knowledge of active teaching strategies among the faculty for their better professional qualification as a mediator in the training process of accountants.
\end{abstract}

Keywords: Active teaching strategies. Accounting. Teacher. 


\section{INTRODUÇÃO}

Com as diversas mudanças decorrentes em todo o cenário brasileiro, inclusive, no educacional, se torna constante a busca por novidades e atualizações nas estratégias de ensino no âmbito universitário, tornando-se essencial um olhar sobre as formas utilizadas nas metodologias de ensino por parte dos docentes.

O método de ensino tradicional consiste ao docente o papel de sujeito ativo e ao discente uma posição passiva no processo de ensino e aprendizagem. Este método apresenta como característica principal a limitação quanto à troca de experiências entre os sujeitos, visto que os docentes em questão são caracterizados como possuidor do conhecimento absoluto (PEREIRA, NIYAMA, FREIRE, 2012).

No entanto, a constante necessidade de aperfeiçoamento vem transformando a maneira de ensinar e aprender, todavia, tanto os professores como os alunos podem interagir com as estratégias ativas. Nesse sentido, as estratégias de ensino ativas apresentam diversas nomenclaturas, sendo consideradas modernas para atender melhor ao processo de formação dos alunos. Estas práticas pedagógicas mais atuais também são conhecidas como estratégias de ensino em ação, inovadoras e/ ou método construtivista de ensino, em que os discentes assumem o papel ativo no processo de ensino-aprendizagem (GEWEHR ET AL, 2016; ANTUNES, 2014; SILVA, SANTOS, BISPO, 2015; KRUGER, ENSSLIN, 2013).

Deste modo, as estratégias de ensino ativas corroboram as necessidades de mudanças nas práticas docentes, a fim de melhorar o processo de ensino e aprendizagem. Esta atual perspectiva construtivista está voltada a inserção dos alunos para o mercado de trabalho, e a percepção deles quanto ao protagonismo, aprendizado fundamentado na reflexão crítica, autonomia (FULLERTON, 2010), e a busca pelo autoconhecimento para que seja capaz de autodirecionar o seu aprendizado (LIMA, 2016).

Sendo assim, Silva e Bivatti (2019) atentam que a percepção dos docentes quanto às estratégias de ensino busca promover o desenvolvimento profissional e social dos futuros contadores. Desse modo, as instituições de ensino superior preparam profissionais devidamente capacitados, com habilidades e competências que são tratadas no decorrer do curso.

Com relação ao contexto estudado, tem-se o curso de Ciências Contábeis, cuja localidade é em Mamanguape/Paraíba/Brasil. Este campus universitário foi fundado em 2006, 
contribuindo na região no tocante ao caráter da qualificação profissional, contando com aproximadamente 25 docentes vinculados ao curso, e um total de 40 disciplinas pertinentes ao semestre investigado 2019.2.

Assim, o artigo objetiva analisar a percepção dos docentes do curso de ciências contábeis do campus IV/UFPB/Brasil em relação à utilização das estratégias de ensino ativas. Assim, o estudo tem-se como contribuição teórica um conhecimento mais aprofundado sobre estratégias de ensino ativas, e contribuição prática para o corpo docente do curso pesquisado por possibilitar um olhar apurado de como os professores vem se utilizando de estratégias de ensino ativas para fomento de suas aulas, auxiliando na formação mais qualificada dos estudantes de contábeis.

\section{AS ESTRATÉGIAS DE ENSINO E SEUS DESDOBRAMENTOS}

Diante das inúmeras mudanças que ocorrem no atual cenário educacional, observamse também as transformações relacionadas ao ensino e aprendizagem, em que surgem novas exigências para melhorar o desenvolvimento de competências e habilidades dos docentes e discentes, primordialmente, alterando a concepção predeterminada do que é ser docente.

Além disso, busca-se com a implementação de estratégias de ensino distintas, a partir de uma concepção construtivista, contribuir na formação crítica e reflexiva dos discentes, mudando a si mesmo e o ambiente em que está inserido, e assim proporcionar uma visão abrangente no seu processo de aprendizagem (DIESEL; BALDEZ; MARTINS, 2017; LIMA; SILVA, 2012; KRUGER; ENSSLIN, 2013).

Deste modo, existe a necessidade de ações que possam auxiliar esse processo de construção do conhecimento, a partir das estratégias de ensino. Assim, as estratégias de ensino são "práticas pedagógicas operacionalizadas por meio de conjuntos de atividades escolares propostas pelos professores com vistas a alcançar a aprendizagem de determinados conhecimentos, valores e comportamentos" (TRAVERSINI; BUAES, 2009, p. 145).

Destaca-se a existência de duas perspectivas referentes às estratégias de ensino: o primeiro se associa ao método tradicional, cujo discente é visto como passivo, recebendo as informações sem aplicar o senso crítico, e o docente é visto como o possuidor do conhecimento absoluto. Por outro lado, as novas estratégias de ensino entendidas como ativas ou inovadoras, o aluno passa a executar o papel ativo, e consequentemente, passa a existir o 
compartilhamento de ideias entre o aluno e o professor, entre o aprender e o ensinar (GEWEHR ET AL, 2016; PEREIRA, 2012).

Ainda nos dias atuais, o método tradicional é o mais utilizado na graduação, em que o docente é o sujeito ativo no processo de ensino e aprendizagem, isto é, o proprietário do conhecimento, e tem como atribuição repassá-los aos discentes, normalmente, através de aulas teóricas (aulas expositivas). Logo, este método apresenta como a principal vantagem o fato do professor ter o maior controle das aulas (PINHO ET AL, 2010). Todavia, acarretando aos alunos apenas assimilar superficialmente o que foi repassado pelos docentes (KRUGER; ENSSLIN, 2013), e não estimulando os alunos ao debate e o senso crítico (BACKES ET AL, 2010).

Inclusive, podem ser citadas outras estratégias tradicionais de ensino, como por exemplo, o quadro negro, giz e livro didático (ANTUNES, 2014), a apostila didática, a qual contém o assunto da disciplina e, a resolução de exercícios-modelo por parte do docente e proposição de exercícios para os discentes (KURI; SILVA; PEREIRA, 2006).

Sendo assim, o método tradicional de ensino apresenta certos aspectos que já não correspondem à realidade dinâmica do atual ambiente de aprendizagem, quando comparado às estratégias de ensino ativas, até mesmo em virtude das novas configurações estruturais e institucionais das universidades (LIMA; SILVA, 2017). Para Diesel, Baldez, Martins (2017) sobre a busca pelo aprimoramento do ensino e aprendizagem, destacam-se a valorização da inovação em sala de aula por parte dos docentes e discentes para se diversificar no cenário educacional, através da criação, renovação e até mesmo a invenção de estratégias ativas.

Assim, estes estudos foram trazendo contribuições que se desdobraram em diferentes denominações das estratégias de ensino, cujos tipos considerados modernos para atender melhor ao processo formativo dos alunos foram classificados como estratégias de ensino em ação, inovadoras ou ativas (ANTUNES, 2014; SILVA; SANTOS; BISPO, 2015). Ademais, há outras nomenclaturas que também buscam designar estas estratégias, como por exemplo, quando se refere à utilização do método construtivista de ensino (KRUGER; ENSSLIN, 2013).

Em consequência, Pereira (2012) diz que as metodologias ativas se referem ao processo de organização da aprendizagem (estratégias didáticas), cuja centralidade do processo esteja, efetivamente, no aluno. Todavia, a eficácia desse processo se relaciona com 
as estratégias de ensino ativas adotadas pelos docentes e as responsabilidades dos discentes para a devida execução das atividades propostas.

As estratégias inovadoras surgiram na área das ciências da Saúde, conforme explica Paiva et al (2016), na qual a expansão supera este campo de conhecimento, alcançando as ciências Sociais e Humanas, tendo a expectativa que esses profissionais possam solucionar os problemas através da reflexão e análise crítica de cada contexto em particular. Os autores complementam que as estratégias de ensino ativas rompem com o modelo tradicional de ensino e fundamentam-se em uma pedagogia problematizadora, em que o aluno é estimulado a assumir uma postura ativa em seu processo de aprender.

Portanto, as estratégias inovadoras de ensino atribuem significados positivos no processo de ensino e aprendizagem, dado que estas estratégias são diversificadas e precisam ser exploradas, selecionadas e usadas pelos professores a fim de contribuir na formação crítica e reflexiva dos alunos. Desta maneira, busca-se o entendimento a respeito da definição e os tipos de estratégias existentes.

\subsection{PECULIARIDADES DAS ESTRATÉGIAS DE ENSINO ATIVAS}

As estratégias de ensino ativas buscam mais entrosamento e participação dos alunos com o assunto abordado em sala de aula, encorajando-os nas atividades designadas pelos docentes (novas perspectivas de ensino), e auxiliando-os na compreensão da teoria com a prática (HOSAL-AKMAN; SIMGA-MUGAN, 2010).

Estas estratégias proporcionam novos conceitos às aulas, apresentando capacidade para despertar a curiosidade e motivação dos alunos, levando-os a assumir uma postura ativa na aprendizagem, visto que as suas experiências, saberes e opiniões são consideradas como precursores para a construção do conhecimento (DIESEL; BALDEZ; MARTINS, 2017). Por conseguinte, há inúmeras possibilidades para que os docentes desenvolvam as estratégias de ensino ativas, podendo se utilizar de diferentes tipos, como a estratégia da problematização, o arco de marguerez, aprendizagem baseada em problemas (problem-based learning - PBL), aprendizagem baseada em equipe (team-based learning - TBL), seminários, relato crítico de experiência, mesas-redondas, debates temáticos, oficinas, leitura comentada, apresentação de filmes, interpretações musicais, dramatizações, dinâmicas lúdico-pedagógicas, entre outros (SIQUEIRA, 2009). 


\section{CONHECIMENTOS SOBRE ESTRATÉGIAS DE ENSINO ATIVAS: REVELAÇÕES E CONSTATAÇÕES NO CORPO DOCENTE DE UM CURSO DE CONTÁBEIS EM UMA INSTITUIÇÃO DE ENSINO SUPERIOR BRASILEIRA \\ DOI: https://doi.org/10.5007/1983-4535.2021.e75780}

Além destas, destacam-se outras estratégias inovadoras, como por exemplo, o estudo de caso interdisciplinar que visa inserir o futuro profissional em uma visão teórico-prática, a utilização de notícias (fatos) reais veiculados pela mídia (BOAVISTA, 2004), o uso de filmes, fórum de debates e simpósios, dentre outros (SILVA ET AL, 2012).

No quadro 01 são apresentadas algumas estratégias de ensino ativas que podem contribuir para a construção do processo de ensino e aprendizagem na formação dos discentes. Esses tipos foram elencados a partir de pesquisas encontradas sobre a abordagem dos mesmos em sala de aula no âmbito acadêmico.

Quadro 01 Tipos de estratégias de ensino ativas e seus significados

\begin{tabular}{|c|c|}
\hline $\begin{array}{l}\text { ESTRATÉGIAS DE } \\
\text { ENSINO ATIVAS }\end{array}$ & SIGNIFICADOS \\
\hline Mapas conceituais & $\begin{array}{l}\text { Serve como instrumento ou recurso para facilitar o aprendizado dos conteúdos e } \\
\text { amplia a sua significação para a pessoa que o utiliza. }\end{array}$ \\
\hline $\begin{array}{l}\text { Leitura em sala de aula/ } \\
\text { Estudo dirigido }\end{array}$ & $\begin{array}{lccccc}\text { Auxilia na } & \text { participação } & \text { do } & \text { aluno } & \text { de } & \text { maneira } \\
\text { efetiva na sala de aula e tenha consistência de seus posicionamentos. } & \\
\end{array}$ \\
\hline Jogos de empresas & $\begin{array}{l}\text { Desenvolve nos alunos a habilidade em tomar decisões com base nos dados que } \\
\text { são apresentados, e trazer para a prática a resolução dos problemas que muitas } \\
\text { vezes são encontrados nas empresas, deste modo, capacitando os discentes para } \\
\text { o desenvolvimento de habilidades e experiências. }\end{array}$ \\
\hline $\begin{array}{l}\text { PBL (Aprendizagem } \\
\text { baseada em problemas) }\end{array}$ & $\begin{array}{l}\text { Valoriza experiências concretas e problematizadoras, com forte motivação } \\
\text { prática e estímulo cognitivo para solicitar escolhas e soluções criativas. Centra- } \\
\text { se no estudante e é usado hoje de forma globalizada, em uma instrução mais } \\
\text { elevada. }\end{array}$ \\
\hline Debates em sala de aula & $\begin{array}{l}\text { Promove o diálogo que conduz a uma transformação social, uma vez que a } \\
\text { participação democrática cria espaços para uma aprendizagem significativa por } \\
\text { meio da capacidade de reflexão crítica. }\end{array}$ \\
\hline Trabalhos em grupo & $\begin{array}{l}\text { Possibilita ao aluno adquirir conhecimento acerca do conteúdo da disciplina } \\
\text { estudada e também desenvolver habilidades quanto ao pensamento e à } \\
\text { argumentação, uma vez que essa forma de trabalho gera discussões entre as } \\
\text { equipes que, por sua vez, auxiliam o aluno a tomar decisões e defender seu } \\
\text { ponto de vista. }\end{array}$ \\
\hline Seminários dinâmicos & $\begin{array}{l}\text { Busca-se socializar, com o grupo espectador, alternativas aos questionamentos } \\
\text { discutidos, visando estimular a produção do conhecimento de forma cooperativa, } \\
\text { permitindo aos alunos a interação com o saber e a aquisição de uma } \\
\text { aprendizagem de qualidade. }\end{array}$ \\
\hline Estudo de caso & $\begin{array}{l}\text { Direciona aos discentes a possibilidade de se formar um pensamento crítico e } \\
\text { reflexivo na resolução de problemas que são aplicados em uma determinada } \\
\text { questão profissional real ou ilusória. }\end{array}$ \\
\hline Método de caso & $\begin{array}{l}\text { Objetiva a análise de situações reais do contexto organizacional para conduzir os } \\
\text { alunos a uma mobilização de recursos e saberes em um processo de tomada de } \\
\text { decisão. Assim, possibilita aos alunos a vivência de experiências pessoais que } \\
\text { servem para desencadear o processo de reflexão e compreensão do mundo real. }\end{array}$ \\
\hline $\begin{array}{l}\text { Aulas práticas e de } \\
\text { laboratório }\end{array}$ & $\begin{array}{l}\text { Leva ao alcance de uma abordagem profunda de aprendizagem, dado que } \\
\text { propicia maior participação e interação dos alunos com o conteúdo proposto. } \\
\text { Pretende alcançar a eficiência na aprendizagem por meio da união da teoria com } \\
\text { a prática profissional específica. }\end{array}$ \\
\hline
\end{tabular}




\section{CONHECIMENTOS SOBRE ESTRATÉGIAS DE ENSINO ATIVAS: REVELAÇÕES E CONSTATAÇÕES NO CORPO DOCENTE DE UM CURSO DE CONTÁBEIS EM UMA INSTITUIÇÃO DE ENSINO \\ SUPERIOR BRASILEIRA \\ DOI: https://doi.org/10.5007/1983-4535.2021.e75780}

\begin{tabular}{|l|l|}
\hline \multicolumn{1}{|c|}{$\begin{array}{c}\text { ESTRATÉGIAS DE } \\
\text { ENSINO ATIVAS }\end{array}$} & \multicolumn{1}{c|}{ SIGNIFICADOS } \\
\hline $\begin{array}{l}\text { Aprendizagem baseada em } \\
\text { artigos científicos }\end{array}$ & $\begin{array}{l}\text { Atende ao ensino e aprendizagem de conteúdos específicos de disciplinas dos } \\
\text { cursos de graduação; aprimoramento de habilidades de comunicação oral e } \\
\text { escrita em linguagem científica; familiarização com a literatura primária } \\
\text { (localização, reconhecimento de características, leitura crítica e compreensão); } \\
\text { compreensão sobre o processo de construção do conhecimento científico e } \\
\text { familiarização com as atividades de pesquisa científica. }\end{array}$ \\
\hline Simulação & $\begin{array}{l}\text { Estimula os estudantes a terem iniciativas empresariais, compreendendo melhor } \\
\text { o ambiente organizacional. Exercita a capacidade de filtrar informações, } \\
\text { gerenciar o tempo e atuar conscientemente no processo de tomada de decisão } \\
\text { diante de situações complexas. }\end{array}$ \\
\hline Visitas técnicas e excursões & $\begin{array}{l}\text { Ocorre mediante a integração do que foi exposto em sala de aula, em que os } \\
\text { alunos participam observando e anotando os dados para, posteriormente, fazer } \\
\text { um relatório e levá-lo para debate em sala de aula. }\end{array}$ \\
\hline $\begin{array}{l}\text { HQ (História em } \\
\text { Quadrinho) }\end{array}$ & $\begin{array}{l}\text { Serve para instigação ao debate e a reflexão sobre um determinado tema, } \\
\text { podendo ajudar os alunos a expressarem e representarem uma situação } \\
\text { profissional que caracterize a aplicação do conhecimento teórico no contexto da } \\
\text { prática gerencial. }\end{array}$ \\
\hline
\end{tabular}

Fonte: Elaboração própria (2019).

Tais estratégias de ensino ativas apresentadas fomentam o desenvolvimento da autonomia e a capacidade reflexiva e crítica dos discentes por meio das atividades realizadas em sala de aula pelo professor, proporcionando o levantamento de questionamentos, bem como desafiando os a transformarem suas visões de mundo na medida em que compreendem os conhecimentos adquiridos e ressignificam os já absorvidos. Deste modo, os discentes assumem a corresponsabilidade na construção do seu aprendizado. E isso ocorre, como alegam Lima e Silva (2012), para que os estudantes conduzam o seu processo de aprendizagem de maneira mais efetiva e condizente com a sua atuação profissional.

Em contrapartida, as estratégias de ensino ativas adotadas pelos docentes podem se tornar limitadas e vulneráveis, caso não haja participação dos discentes de forma efetiva (MOREIRA, 2011). Dessa maneira, caso os alunos não se interessem em participar das atividades com afinco, isto acarreta resultados desfavoráveis na construção de uma aprendizagem significativa.

Sendo assim, enfatiza-se que não importa qual seja a estratégia de ensino utilizada, se não houver o interesse dos alunos em aprender, consequentemente, haverá falhas no processo de aprendizagem uma vez que se torna fundamental a busca pelo autoconhecimento para que o aluno seja capaz de autodirecionar o seu aprendizado (LIMA, 2016). Por outro lado, quando os alunos demonstram interesse em aprender, então, é de responsabilidade do docente 
compreender a metodologia utilizada de tal forma que sua escolha traduza uma concepção clara daquilo que intenciona obter como resultado (GEWEHR ET AL, 2016).

\subsection{O PAPEL DOCENTE NO DESENVOLVIMENTO DE ESTRATÉGIAS DE ENSINO ATIVAS}

Com as novas perspectivas exigidas quanto ao ensino e aprendizagem, entende-se que o papel dos docentes em relação à elaboração de suas estratégias de ensino se volta para o desenvolvimento de competências que conduzam os estudantes ao trabalho em equipe e à cooperação. Isso com o intuito de contribuir para uma formação que incentive o senso crítico e reflexivo, assim como a capacidade de tomar decisões a partir de uma visão holística sobre o ambiente social e organizacional.

Nesse sentido, na atual perspectiva, os docentes passaram a ter o papel para orientar não somente a classe, mas os grupos e os alunos individualmente. Sendo assim, os professores têm a incumbência de fazer com que os discentes aprimorem suas competências e habilidades, inclusive, opinar sobre a formação da mentalidade do aluno, de sua visão de mundo, dos valores e do modo como está inserido na sociedade (OPDECAM; EVERAERT, 2012; MORAN, 2015).

Portanto, o papel dos professores traz características fundamentais que transcendem os limites da sala de aula, contribuindo no processo de ensino e aprendizagem. Assim, as estratégias de ensino ativas se tornam um desafio tanto para os docentes na escolha e utilização das estratégias quanto para os discentes no processo de ensino e aprendizagem, no qual alguns dos desafios são as carências de conhecimento dos docentes sobre as estratégias de ensino em ação, falta de apoio institucional e governamental, desinteresse de docentes e discentes, elevado número de alunos em sala de aula, dificuldade de recursos e estrutura, imaturidade de estudantes, tempo limitado e políticas pedagógicas inadequadas (MAZZIONI, 2013; ROMANOWSKY; BEUREN, 2002).

Por sua vez, ressalta-se a relevância das práticas docentes auxiliando na construção do conhecimento e formação dos alunos, sendo fundamental que o papel dos professores seja revisto em sua ação profissional, uma vez que estes exercem um papel multidimensional por se envolverem em atividades de ensino, pesquisa, extensão e gestão universitária concomitantemente. Isso leva a repensar seu comprometimento na renovação de suas 
estratégias de ensino para que tenham como foco a qualidade do processo formativo do aluno (LIMA; MACEDO; SAEGER, 2019).

\subsection{AS ESTRATÉGIAS DE ENSINO SOB O PRISMA DO ENSINO EM CONTÁBEIS}

Nesse novo cenário educacional, o dinamismo do mundo moderno aponta que no curso de Ciências Contábeis os docentes necessitam de atualização didática para compreender as diversas possibilidades quanto ao uso das estratégias de ensino ativas, a fim de facilitar e aprimorar o processo de ensino e aprendizagem, visto que, os docentes sentem-se

pressionados por um ambiente externo exigente e, indiscutivelmente, pelo dever de proporcionar uma educação de alto nível para os futuros contadores (MAZZIONI, 2013).

Sendo assim, a percepção dos docentes quanto às estratégias de ensino contribui positivamente para a formação profissional e social dos alunos de contabilidade (SILVA; BIVATTI, 2019). Dentro do contexto do Ensino Superior, primordialmente, no curso de Ciências Contábeis, as estratégias de ensino devem ser aplicadas com o objetivo de propor aos discentes o desenvolvimento de habilidades e competências exigidas pelo mercado de trabalho (CATRINCK ET AL, 2017), além de favorecer a contextualização das disciplinas por meio de estratégias ativas que levem situações reais para a sala de aula, em que os alunos possam refletir sobre o tema proposto e estruturar uma análise crítica sobre o assunto (MADUREIRA; SUCCAR; GOMES, 2011).

Buckhaults e Fisher (2011) corroboram que as estratégias de ensino ativas podem incentivar o aprendizado dos alunos por meio do desenvolvimento de habilidades de análise, tomada de decisão e comunicação. Mazzioni (2013) e Leal e Borges (2016) consideram que alguns fatores influenciam na escolha das estratégias de ensino ativas na área contábil a ser aplicadas em sala de aula, com destaque para a experiência adquirida pela atuação docente, a replicação de modelos observados, utilização de exercícios, o plano de aula previamente elaborado, tipo de aula (teórica x prática), relevância do assunto/tema, os objetivos e a ementa da disciplina, além do perfil dos estudantes e o tempo disponível para a aula, entre outros.

Para Marques e Biavatti (2019), o conhecimento e a seleção da estratégia de ensino colaboram para o desenvolvimento da realização do trabalho dos professores, influenciando nos resultados obtidos pelos alunos na avaliação da aprendizagem. Portanto, entende-se que as estratégias de ensino ativas são propulsoras para o sucesso do processo de ensinoaprendizagem. Por fim, no curso de Ciências Contábeis a utilização das estratégias de ensino 
ativas contribui substancialmente na formação dos discentes, pois pode desenvolver o pensamento crítico, a aprendizagem contínua e a tomada de decisão (BECKER, 2013; LEAL; BORGES, 2016; SILVA; BIAVATTI, 2019).

\section{METODOLOGIA}

A pesquisa é de cunho quantitativo, na qual consiste na objetividade, formando um afastamento entre o sujeito e o objeto do conhecimento, além de esclarecer que essa neutralidade do pesquisador transmite mais confiabilidade a pesquisa (SOUZA; KERBAUY, 2017).

O presente trabalho busca a compreensão a respeito do corpo docente de uma instituição de ensino superior, sendo esta a Universidade Federal da Paraíba - UFPB, Campus IV. Este Campus universitário está situado na cidade de Mamanguape/PB, e conta com aproximadamente 25 docentes do Curso de Ciências Contábeis atuando no período 2019.2. Além disso, abarcando um total de cerca de 40 disciplinas cadastradas referentes aos períodos desse semestre.

O instrumento utilizado para a pesquisa de campo realizada a partir de abril/2020 foi um questionário estruturado via google forms que conta com seis seções, são elas: a primeira seção é apenas a descrição da pesquisa, a segunda seção trata do perfil dos docentes (composta por 06 questões), a terceira seção trata do uso das estratégias de ensino ativas (08 questões), posteriormente, a quarta e quinta seções são sobre os objetivos de estudo da pesquisa (13 questões elaboradas de acordo com a escala de Likert), e por fim, a sexta que traz uma avaliação final dos respondentes (02 questões) sobre as estratégias de ensino ativas no Campus IV/ UFPB. Ou seja, ao total são 29 questões aplicadas e que se destinam aos respondentes via meio eletrônico: e-mail/whatsapp.

A aplicação do questionário tem o objetivo de conhecer detalhadamente o perfil dos respondentes sobre a utilização das estratégias de ensino ativas em suas turmas, reconhecendo há quanto tempo utiliza, e até mesmo há quanto tempo leciona no curso de contabilidade, assim como na disciplina.

Deste modo, a pesquisa conta inicialmente com a coleta de dados junto ao Departamento, e também a Coordenação do curso de Ciências Contábeis com o objetivo de identificar nos planos de ensino de cada professor as suas estratégias de ensino, e também conta com as buscas de informações por meio do SIGAA - Sistema Integrado de Gestão de 
Atividades Acadêmicas. Além de identificar os docentes que ministram aulas no referido curso através de categorias de análise a serem desenvolvidas.

O processo de análise da pesquisa ocorreu por meio da estatística descritiva que, segundo Gerarhdt e Silveira (2009), implica no processamento de dados através da geração, da apresentação dos dados e da interpretação, sendo representada por meio de gráficos ou tabelas com o intuito de proporcionar um melhor entendimento e clareza dos seus resultados.

\section{ANÁLISE E DISCUSSÃO DOS RESULTADOS}

As respostas encontradas no questionário mostram que de um total de 22 docentes vinculados ao Campus IV/UFPB referente ao curso de Ciências Contábeis no período 2019.2, foram obtidas 18 respostas que serviram para a composição desta análise, sendo assim, um total de $81,82 \%$ de aproveitamento.

Deste modo, identificando o perfil dos respondentes se observa que a maioria são mulheres, possuem entre 31 e 40 anos de idade, com titulação de Mestrado (55,6\%) e Doutorado $(38,9 \%)$. Vale salientar que predominantemente os cargos são efetivos, e a maioria das disciplinas obrigatórias, em que 44,4\% dos docentes são da área específica de contábeis, e os demais são de outras áreas como administração, economia, direito, finanças e letras.

Com o aprofundamento sobre o perfil dos docentes do curso de contabilidade do Campus IV/UFPB, considerando algumas variáveis relevantes relacionadas ao tempo de docência. O quadro 02 apresenta os resultados.

Quadro 02 Perfil dos docentes do Curso de Ciências Contábeis, Campus IV

\begin{tabular}{|l|c|c|c|c|c|c|c|c|}
\hline $\begin{array}{c}\text { Tempo de carreira } \\
\text { docente }\end{array}$ & QTD & $\mathbf{( \% )}$ & $\begin{array}{c}\text { Tempo de } \\
\text { docência } \\
\text { no Campus IV }\end{array}$ & QTD & (\%) & $\begin{array}{c}\text { Tempo de docência } \\
\text { no Curso de Ciências } \\
\text { Contábeis, Campus IV }\end{array}$ & $\begin{array}{c}\text { QTD } \\
\text { (\%) }\end{array}$ \\
\hline Menos de 5 anos & 1 & $5,6 \%$ & Menos de 3 anos & 4 & $22,2 \%$ & 6 meses & \multicolumn{1}{|c|}{$11,1 \%$} \\
\hline Entre 5 e 10 anos & 2 & $11,1 \%$ & Entre 3 e 5 anos & 2 & $11,1 \%$ & Entre 1 e 3 anos & 3 & $16,7 \%$ \\
\hline Entre 10 e 15 anos & 9 & $50 \%$ & Entre 5 e 7 anos & 1 & $5,6 \%$ & Entre 3 e 9 anos & 4 \\
\hline Entre 15 e 20 anos & 5 & $27,8 \%$ & Entre 7 e 10 anos & 4 & $22,2 \%$ & Entre 9 e 13 anos & 6 & $33,3 \%$ \\
\hline Entre 20 e 30 anos & 1 & $5,6 \%$ & Mais de 10 anos & 7 & $38,9 \%$ & Mais de 13 anos & 2 \\
\hline Mais de 30 anos & 0 & 0 & --- & --- & --- & Não informado & $11,1 \%$ & $5,6 \%$ \\
\hline
\end{tabular}

Fonte: Elaboração própria, (2020).

Os docentes do curso de contabilidade possuem demasiado tempo de carreira, inclusive, muitos atuam no curso desde a criação do Campus IV. Por isso, corroborando com os pensamentos de Mazzioni (2013) e Leal e Borges (2016), a experiência adquirida pela 
atuação docente é um dos fatores que influenciam na escolha das estratégias de ensino ativas na área contábil a ser aplicadas em sala de aula, pois capacita profissionais com ampla competência, atitudes e habilidades para designar suas funções com eficiência.

Além do mais, o tempo de atuação no curso de contabilidade pode proporcionar um maior entendimento sobre quais são as atuais necessidades dos alunos e as possíveis mudanças no processo de ensino-aprendizagem. Nesse sentido, de acordo com Gewehr et al. (2016) e Pereira (2012) promover a troca de experiências entre os sujeitos é um aprendizado mais satisfatório para os alunos.

Portanto, a experiência profissional dos professores quanto ao tempo de carreira, tempo de docência no Campus IV, e o tempo no curso de Ciências Contábeis são fatores que podem contribuir no avanço da utilização das estratégias de ensino ativas, pois estas estratégias são baseadas na maneira como o conteúdo das disciplinas é posto aos alunos, nas possíveis inovações das atividades em sala de aula, e na maior participação dos alunos nessas atividades propostas. E assim, conforme Silva e Bivatti (2019), formar profissionais com sólidos domínios acadêmicos, científicos e tecnológicos no seu campo de atuação, além de promover o desenvolvimento social dos futuros contadores.

Diante disso, no Projeto Pedagógico de Curso (PPC) de Ciências Contábeis e na matriz curricular, são apresentadas as classificações das disciplinas ofertadas, sendo estas um total de 40 disciplinas (em que 24 disciplinas são obrigatórias e 16 disciplinas são complementares obrigatórias), e ainda, cerca de 30 disciplinas são optativas (mas somente duas estão disponíveis no período 2019.2), além das disciplinas complementares flexivas que são compostas por tópicos especiais em Contabilidade.

Assim, o detalhamento nos planos de curso/ensino referente às disciplinas do período 2019.2 foram analisadas no tocante as estratégias de ensino utilizadas por docentes. E de um total de 40 disciplinas, foram encontrados 39 planos de cursos cadastrados (ou seja, apenas 1 docente não cadastrou seu plano de curso), portanto, houve um total de $97,5 \%$ de aproveitamento para a composição desta análise.

Deste modo, com base nos planos de curso das disciplinas que lecionam, o quadro 03 revela os tipos de estratégias de ensino mais utilizadas em sala de aula.

Soma-se um total de 140 estratégias de ensino citadas nos planos de cursos cadastrados, ou seja, cada plano de curso contou com a apresentação de diversas estratégias. 
Inclusive, que as estratégias de ensino ativas foram utilizadas parcialmente, ou seja, ainda são pouco utilizadas.

Quadro 03 As estratégias de ensino utilizadas com base nos planos de curso

\begin{tabular}{|l|c|c|}
\hline \multicolumn{1}{|c|}{ Estratégias de ensino } & QTD & \% \\
\hline Aulas expositivas, dialogadas/ participativas & 34 & $87,18 \%$ \\
\hline $\begin{array}{l}\text { Orientação de trabalhos e dinâmicas individuais e em } \\
\text { grupo }\end{array}$ & 23 & $58,97 \%$ \\
\hline Leitura de textos, debates e discussões & 22 & $56,41 \%$ \\
\hline Utilização de recursos diversos & 20 & $51,28 \%$ \\
\hline Resolução de exercícios de fixação, práticas didáticas & 12 & $30,77 \%$ \\
\hline Seminários & 9 & $23,08 \%$ \\
\hline Estudo de casos & 7 & $17,95 \%$ \\
\hline Análise de filmes e textos, utilização de arte & 4 & $10,26 \%$ \\
\hline Rodas de conversas & 2 & $5,13 \%$ \\
\hline Visitas técnicas e acompanhadas & 2 & $5,13 \%$ \\
\hline Orientação de pesquisas & 2 & $5,13 \%$ \\
\hline Estudo dirigido & 2 & $5,13 \%$ \\
\hline Estudos em laboratório & 1 & $2,56 \%$ \\
\hline \multicolumn{1}{|c|}{ TOTAL } & $\mathbf{1 4 0}$ & --- \\
\hline
\end{tabular}

Fonte: Elaboração própria, (2020).

Por esse motivo, quase a totalidade dos docentes afirmaram que utilizam as aulas expositivas-dialogadas como a principal estratégia de ensino, e assim, esse elevado percentual de utilização corrobora com o pensamento de Pinho et al. (2010) em que a principal vantagem dessas aulas expositivas (estratégias de ensino tradicionais) é o fato do professor ter domínio das aulas, e o aluno exercer o papel passivo, isto é, apenas recebendo as informações sem aplicar o senso crítico.

Por outro lado, como as aulas também são dialogadas/participativas (estratégias de ensino ativas), isso significa que conforme afirmam Diesel, Baldez, Martins (2017) o intuito é valorizar a inovação em sala de aula por parte dos professores e alunos, e conforme Paiva et al. (2016) romper com o modelo tradicional de ensino, além de mostrar as vantagens dessas estratégias ao contribuir no processo de ensino-aprendizagem, em que o aluno é incentivado a assumir uma postura ativa.

Além disso, alguns professores afirmam que as estratégias de ensino ativas podem motivar os alunos para estudar a disciplina, e se aprofundarem na pesquisa. Por isso, o quadro 04 mostra a utilização das estratégias de ensino ativas como atividades avaliativas (total ou parcial). 
Quadro 04 Estratégias de ensino ativas como atividade avaliativa

\begin{tabular}{|c|c|c|}
\hline Estratégias de ensino ativas como atividade avaliativa & QTD & $\mathbf{\%}$ \\
\hline Utilizam apenas provas objetivas/ subjetivas & 3 & $7,69 \%$ \\
\hline $\begin{array}{l}\text { Utilizam provas, e demais atividades participativas em } \\
\text { sala de aula }\end{array}$ & 22 & $56,41 \%$ \\
\hline $\begin{array}{l}\text { Não utilizam provas, apenas atividades participativas em } \\
\text { sala de aula }\end{array}$ & 14 & $35,90 \%$ \\
\hline TOTAL & $\mathbf{3 9}$ & $\mathbf{1 0 0 \%}$ \\
\hline
\end{tabular}

Fonte: Elaboração própria, (2020).

Os resultados encontrados nos planos de cursos serviram para comparar com os resultados obtidos no questionário, e assim percebe-se que a maioria dos docentes de contabilidade utilizam parcialmente as estratégias de ensino ativas em suas aulas, inclusive, como atividade avaliativa. Ressalta-se, que alguns docentes ainda possuem certas dificuldades sobre a utilização das estratégias de ensino ativas ou inovadoras com relação ao conhecimento (teórico x prático) e aplicação dessas estratégias.

Deste modo, com relação à utilização das estratégias de ensino em sala de aula a maioria dos respondentes $(61,1 \%)$ considera que as estratégias de ensino ativas contribuem com a sólida formação técnica dos alunos, desenvolvendo habilidades e competências exigidas pelo mercado de trabalho. E também a formação do cidadão consciente, participativo e transformador da sociedade, ou seja, a maneira como os alunos relacionam conhecimentos e constroem significados, e as características fundamentais que são desenvolvidas em seu perfil.

Assim, a respeito das estratégias de ensino ativas utilizadas, o quadro 05 demonstra quais são as mais utilizadas por docentes do Campus IV/ UFPB.

Os resultados encontrados corroboram com os estudos de Catrinck et al (2017), pois apontam sobre as principais estratégias de ensino utilizadas no curso de ciências contábeis que podem ser mais significativas, comprovando a efetividade no processo de ensinoaprendizagem. Desta maneira, os quadros 06 e 07 referem-se à percepção dos docentes sobre os objetivos de estudo da pesquisa.

Sendo assim, entende-se que os docentes afirmaram que utilizam frequentemente as estratégias de ensino ativas (38,9\%), inclusive como atividade avaliativa (33,3\%), e que mais da metade dos respondentes informaram que sempre realizam o cumprimento das estratégias de ensino conforme a elaboração no plano de ensino/ curso (55,6\%). Além do mais, 66,7\% dos respondentes dizem que estas estratégias de ensino ativas proporcionam maior interação 
dos alunos nas atividades propostas, por isso são importantes no processo de aprendizagem dos alunos, tornando-os mais ativos em sala de aula.

Quadro 05 Estratégias de ensino ativas utilizadas

\begin{tabular}{|l|c|c|}
\hline Estratégias de ensino ativas utilizadas & QTD & $\%$ \\
\hline Aprendizagem baseada em artigos científicos & 16 & $88,9 \%$ \\
\hline Leitura de artigos para estudo dirigido & 16 & $88,9 \%$ \\
\hline Debates de textos e vídeos em sala de aula & 16 & $88,9 \%$ \\
\hline Seminários dinâmicos & 15 & $83,3 \%$ \\
\hline Trabalhos em grupo & 15 & $83,3 \%$ \\
\hline Estudo de caso & 14 & $77,8 \%$ \\
\hline Método de caso & 11 & $61,1 \%$ \\
\hline Relato de filmes/ séries & 9 & $50 \%$ \\
\hline Aulas práticas e de laboratório & 6 & $33,3 \%$ \\
\hline Visitas técnicas e excursões & 5 & $27,8 \%$ \\
\hline PBL (Aprendizagem Baseada em Problemas) & 5 & $27,8 \%$ \\
\hline Mapa Conceitual & 4 & $22,2 \%$ \\
\hline HQ (História em Quadrinho) & 2 & $11,1 \%$ \\
\hline Simulação & 2 & $11,1 \%$ \\
\hline Jogos de empresas & 1 & $5,6 \%$ \\
\hline Brainstorming & 1 & $5,6 \%$ \\
\hline Resolução de Questões & 1 & $5,6 \%$ \\
\hline Mesa redonda & 1 & $5,6 \%$ \\
\hline TOTAL & 140 & --- \\
\hline
\end{tabular}

Fonte: Elaboração própria, (2020).

Quadro 06 Percepção dos docentes sobre os objetivos de estudo da pesquisa em grau de frequência

\begin{tabular}{|c|c|c|c|c|c|c|}
\hline \multicolumn{7}{|c|}{ Grau de Frequência (em porcentagem \%) } \\
\hline Variáveis & Nunca & Raramente & Ocasionalmente & Frequentemente & Sempre & Total \\
\hline $\begin{array}{c}\text { Utilização das estratégias de } \\
\text { ensino ativas em sala de } \\
\text { aula }\end{array}$ & $0 \%$ & $5,6 \%$ & $33,3 \%$ & $38,9 \%$ & $22,2 \%$ & $100 \%$ \\
\hline $\begin{array}{c}\text { Uso das estratégias de } \\
\text { ensino como atividade } \\
\text { avaliativa }\end{array}$ & $11,1 \%$ & $0 \%$ & $22,2 \%$ & $33,3 \%$ & $33,3 \%$ & $100 \%$ \\
\hline $\begin{array}{c}\text { Cumprimento das } \\
\text { estratégias de ensino } \\
\text { conforme elaboração no } \\
\text { plano de ensino/ curso }\end{array}$ & $5,6 \%$ & $0 \%$ & $0 \%$ & $38,9 \%$ & $55,6 \%$ & $100 \%$ \\
\hline $\begin{array}{c}\text { Interação dos alunos nas } \\
\text { atividades propostas }\end{array}$ & $0 \%$ & $0 \%$ & $5,6 \%$ & $66,7 \%$ & $22,2 \%$ & $100 \%$ \\
\hline $\begin{array}{c}\text { Participação em debates/ } \\
\text { reunióes/ palestras } \\
\text { pedagógicas sobre a }\end{array}$ & $5,6 \%$ & $22,2 \%$ & $50 \%$ & $5,6 \%$ & $16,7 \%$ & $100 \%$ \\
$\begin{array}{c}\text { divulgação de estratégias de } \\
\text { ensino entre o corpo docente }\end{array}$ & $\mathbf{2 2 , 3 \%}$ & $\mathbf{2 7 , 8 \%}$ & $\mathbf{1 1 1 , 1 \%}$ & $\mathbf{1 8 3 , 4 \%}$ & $\mathbf{1 5 0 \%}$ & --- \\
\hline \begin{tabular}{c} 
TOTAL \\
\hline
\end{tabular}
\end{tabular}

Fonte: Elaboração própria, (2020). 


\section{CONHECIMENTOS SOBRE ESTRATÉGIAS DE ENSINO ATIVAS: REVELAÇÕES E CONSTATAÇÕES \\ NO CORPO DOCENTE DE UM CURSO DE CONTÁBEIS EM UMA INSTITUIÇÃO DE ENSINO \\ SUPERIOR BRASILEIRA \\ DOI: https://doi.org/10.5007/1983-4535.2021.e75780}

Entretanto, os resultados encontrados mostram que há pouca participação dos professores em debates/reuniões sobre a divulgação dessas estratégias de ensino. Ou seja, essa é uma lacuna que precisa de uma nova abordagem e de mais atenção do corpo docente das instituições de ensino superior, primordialmente, do curso de ciências contábeis. Pois esses novos estudos podem mostrar o caminho das mudanças do papel do professor em sala de aula.

Em continuidade, o quadro 07 mostra outras variáveis relevantes sobre a percepção dos docentes no tocante aos objetivos de estudo da pesquisa.

Quadro 07 Percepção dos docentes sobre os objetivos de estudo da pesquisa em grau de concordância

\begin{tabular}{|c|c|c|c|c|c|c|}
\hline \multicolumn{7}{|c|}{ Grau de Concordância (em porcentagem \%) } \\
\hline Variáveis & $\begin{array}{c}\text { Discordo } \\
\text { Totalmente }\end{array}$ & Discordo & Neutro & Concordo & $\begin{array}{c}\text { Concordo } \\
\text { Totalmente }\end{array}$ & Total \\
\hline $\begin{array}{l}\text { As estratégias ativas são relevantes como } \\
\text { avaliação completa }\end{array}$ & $5,6 \%$ & $0 \%$ & $22,2 \%$ & $22,2 \%$ & $50 \%$ & $100 \%$ \\
\hline $\begin{array}{c}\text { As estratégias de ensino ativas são } \\
\text { consideradas mais dinâmicas e facilitadoras } \\
\text { para o aprendizado }\end{array}$ & $5,6 \%$ & $0 \%$ & $16,7 \%$ & $33,3 \%$ & $44,4 \%$ & $100 \%$ \\
\hline $\begin{array}{l}\text { As estratégias ativas refletem na qualidade da } \\
\text { formação dos alunos }\end{array}$ & $0 \%$ & $5,6 \%$ & $16,7 \%$ & $44,4 \%$ & $33,3 \%$ & $100 \%$ \\
\hline $\begin{array}{c}\text { Essas estratégias ativas são compartilhadas } \\
\text { entre os colegas }\end{array}$ & $0 \%$ & $33,3 \%$ & $38,9 \%$ & $16,7 \%$ & $11,1 \%$ & $100 \%$ \\
\hline $\begin{array}{l}\text { As estratégias de ensino ativas motivam mais } \\
\text { os alunos para participar da aula }\end{array}$ & $0 \%$ & $5,6 \%$ & $16,7 \%$ & $38,9 \%$ & $38,9 \%$ & $100 \%$ \\
\hline $\begin{array}{l}\text { A utilização das estratégias em sala de aula } \\
\text { tem o objetivo de estreitar a relação da teoria } \\
\text { e prática na minha disciplina }\end{array}$ & $5,6 \%$ & $5,6 \%$ & $0 \%$ & $44,4 \%$ & $44,4 \%$ & $100 \%$ \\
\hline $\begin{array}{l}\text { Sinto dificuldades em conhecer e aplicar } \\
\text { estratégias de ensino ativas }\end{array}$ & $16,7 \%$ & $38,9 \%$ & $27,8 \%$ & $16,7 \%$ & $0 \%$ & $100 \%$ \\
\hline $\begin{array}{c}\text { As estratégias de ensino ativas não } \\
\text { influenciam no comprometimento e na } \\
\text { construção de conhecimentos dos alunos }\end{array}$ & $61,1 \%$ & $27,8 \%$ & $0 \%$ & $11,1 \%$ & $0 \%$ & $100 \%$ \\
\hline TOTAL & $94,6 \%$ & $116,8 \%$ & $139 \%$ & $227,70 \%$ & $222,10 \%$ & --- \\
\hline
\end{tabular}

Fonte: Elaboração própria, (2020).

Os resultados encontrados mostram que a maioria dos docentes $(50 \%)$ concordaram totalmente que as estratégias de ensino ativas são relevantes como avaliação completa, e que são consideradas mais dinâmicas e facilitadoras para o aprendizado dos alunos (44,4\%), e assim, pode motivá-los para participar da aula (38,9\%). Para a maioria dos docentes essas estratégias podem influenciar no comprometimento e na construção de conhecimentos $(61,1 \%)$, e também refletir na qualidade da formação dos alunos.

Nessa perspectiva, conforme o PPC, o objetivo em relacionar ações interdisciplinares é para consolidar o conhecimento que os alunos adquirem em cada disciplina, através das atividades teóricas e práticas, isto é, possibilita a aplicação prática dos conhecimentos 


\section{CONHECIMENTOS SOBRE ESTRATÉGIAS DE ENSINO ATIVAS: REVELAÇÕES E CONSTATAÇÕES \\ NO CORPO DOCENTE DE UM CURSO DE CONTÁBEIS EM UMA INSTITUIÇÃO DE ENSINO \\ SUPERIOR BRASILEIRA \\ DOI: https://doi.org/10.5007/1983-4535.2021.e75780}

adquiridos em sala de aula, e fomenta o pensamento crítico dos alunos, por isso $44,4 \%$ dos docentes afirmaram que as estratégias utilizadas têm essa finalidade. Todavia, enfatizando o que foi explicado no quadro 06, observou-se que também há uma carência na divulgação das estratégias de ensino ativas entre o corpo docente.

Além disso, observou-se que muitos professores são neutros $(38,9 \%)$, e outros docentes discordaram (33,3\%) sobre o compartilhamento dessas estratégias. Ou seja, além de não haver a devida divulgação das estratégias de ensino ativas, consequentemente, há também pouco interesse e participação dos docentes quanto ao aprofundamento do tema. Ademais, conforme o estudo de Mazzioni (2013) esse desinteresse pode ser justificado devido aos inúmeros desafios e dificuldades que prejudicam as práticas docentes, contudo, relacionadas desde a formação dos professores.

Inclusive, a respeito das dificuldades em conhecer e aplicar as estratégias de ensino ativas, os resultados demonstram que a maioria dos docentes não sentem dificuldades, já que conhecem e aplicam as estratégias de ensino ativas em sala de aula. Por outro lado, os demais respondentes não conhecem e/ou não aplicam essas estratégias inovadoras. Por isso podem ser neutros sobre as dificuldades encontradas. Sendo assim, com relação as principais dificuldades encontradas, o quadro 08 mostra a percepção dos docentes sobre os fatores mais relevantes.

Quadro 08 As principais dificuldades encontradas pelos docentes de contabilidade, Campus IV

\begin{tabular}{|l|c|}
\hline \multicolumn{1}{|c|}{ Descrição das principais dificuldades } & Porcentagem (\%) \\
\hline Imaturidade e/ ou desmotivação dos alunos & $(88,9 \%)$ \\
\hline Dificuldade de recursos e estrutura pela instituição superior & $(83,3 \%)$ \\
\hline Políticas pedagógicas inadequadas & $(33,3 \%)$ \\
\hline Tempo limitado para a execução de atividades & $(27,8 \%)$ \\
\hline Elevado número de alunos em sala de aula & $(27,8 \%)$ \\
\hline Carência de estudos na área de contabilidade & $(16,7 \%)$ \\
\hline
\end{tabular}

Fonte: Elaboração própria, (2020).

Desse modo, para a maioria dos docentes pesquisados a principal lacuna encontrada no processo de ensino-aprendizagem é devido à imaturidade e/ou desmotivação dos alunos, pois não participam das aulas ou, quando participam, preferem não interagir nas atividades. Para Mazzioni (2013) e Diesel, Baldez, Martins (2017) o elemento crucial que causa a desmotivação dos alunos ocorre devido à falta de integração entre a teoria e a prática. Sendo assim, os alunos precisam ser desafiados para uma postura crítica, e para vivenciar o que aprendem com a aplicação dos assuntos abordados em questões práticas. 
Portanto, essas estratégias de ensino ativas visam provocar uma mudança de cultura do ensino, através da troca de experiências entre os sujeitos envolvidos, cujo intuito é de proporcionar uma aprendizagem mais efetiva aos alunos, atribuindo a responsabilidade de construir seu próprio conhecimento, capacitando-os para a inserção no mercado de trabalho, e assim melhorar a esfera do ensino do curso estudado.

\section{CONSIDERAÇÕES FINAIS}

Este artigo analisou a percepção dos docentes do curso de ciências contábeis do campus IV/UFPB/Brasil em relação à utilização das estratégias de ensino ativas. Para tanto, foi realizado o levantamento do quantitativo de professores que lecionam no mencionado curso a partir da definição de categorias de análise, foi traçado o perfil dos docentes identificados por utilizarem estratégias de ensino ativas em suas salas de aula, e detalhado as estratégias de ensino ativas utilizadas.

Os professores pesquisados utilizam parcialmente as estratégias de ensino ativas nas atividades e avaliações em sala de aula. Percebe-se, também, a carência existente na divulgação das estratégias de ensino ativas entre o corpo docente, podendo ser justificado pelos desafios encontrados em seu campo de atuação, com destaque para o desinteresse dos alunos, dificuldade de recursos e estrutura pela instituição superior, políticas pedagógicas inadequadas, entre outros.

Deste modo, os resultados esclarecem que as estratégias de ensino mais utilizadas por docentes do curso de Ciências Contábeis do Campus IV/UFPB são: Aprendizagem baseada em artigos científicos; Leitura de artigos para estudo dirigido; Debates de textos e vídeos em sala de aula; Seminários dinâmicos; Trabalhos em grupo. Assim, reflete-se que elas são compatíveis com as estratégias ativas cadastradas nos planos de curso/ensino dos docentes. Isso significa que as estratégias de ensino ativas se tornam um dos fatores determinantes para a qualificação docente no âmbito do ensino por contribuir com uma aprendizagem mais significativa para os alunos.

Portanto, espera-se que essa pesquisa tenha colaborado com o ensino de contabilidade, e consequentemente, com a formação dos docentes ao apresentar estratégias de ensino ativas que podem ser utilizadas em sala de aula como estímulo qualitativo na formação discente. Além disso, evidencia reflexões para um aprendizado mais consistente dos alunos, em que eles assumem papel de protagonista no processo de sua formação, desenvolvendo 
competências essenciais, incentivando a autonomia, reflexão e senso crítico, inclusive, possibilita capacitação mais congruente com o mercado de trabalho.

Nada obstante, torna-se necessário explorar mais o tema, pois ainda existe a necessidade em conhecer e difundir melhor as estratégias de ensino ativas. Entretanto, é relevante o desenvolvimento de fóruns de discussões entre o próprio corpo docente para compartilharem mais de suas vivências em salas de aula e definirem o uso de estratégias de ensino ativas mais aplicáveis e cabíveis ao contexto institucional estrutural e cultural existente.

Como diferencial obtido nos resultados e que pode ser útil para as futuras pesquisas seria uma abordagem mais aprofundada sobre as principais dificuldades e desafios encontrados por docentes e discentes do Campus IV/UFPB. Recomenda-se estudos que possam mostrar o olhar dos discentes a respeito das estratégias de ensino ativas utilizadas em sala de aula, e evidenciar como elas podem ser úteis para a formação dos alunos, além dos impactos que as estratégias de ensino ativas podem exercer em sua formação acadêmica e profissional.

\section{REFERÊNCIAS}

ANTUNES, C. Professores e Professauros: Reflexões Sobre a Aula e Práticas Pedagógicas Diversas. Petrópolis: Vozes, 2014.

BACKES, D. S. ET AL. Repensando o ser enfermeiro docente na perspectiva do pensamento complexo. Revista Brasileira de Enfermagem, Brasília, v. 63, n. 3, p. 421-426, 2010.

BECKER, L. L. Self-Regulated Learning Interventions in the Introductory Accounting Course: An Empirical Study. Issues in Accounting Education, v. 28, n. 3, p. 435-460, 2013.

BOAVISTA, P. Estratégias de ensino mais utilizadas pelos professores de Graduação em Ciências Contábeis. Pensar contábil, v. 6, n. 25, 2004.

BUCKHAULTS, J.; FISHER, D. Trends in Accounting Education: Decreasing Accounting Anxiety and Promoting New Methods. Journal of Education for Business, 1. ed., v. 86, p. 31-35, 2011.

CATRINCK, A. W. P. M; SANTOS, I. O; SANTIAGO W. P; LOPES, M. A. S. Análise das estratégias de ensino utilizadas nos cursos de ciências contábeis e administração da Unimontes na visão dos discentes. II Congresso UFU de Contabilidade. Contabilidade, Gestão e Agronegócio. Uberlândia/MG, 2017. 
DIESEL, A.; BALDEZ, A. L. S.; MARTINS, S. N. Os princípios das metodologias ativas de ensino: uma abordagem teórica. Revista Thema. Centro Universitário Univates. Lajeado/ RS, v. 14, n. 1, p. 268-288, 2017.

FULLERTON, J. R. Transformative Learning in College Students: a mixed methods study. Tesis doctoral, University of Nebraska, Nebraska, 2010.

GERHARDT, T. E.; SILVEIRA, D. T. Métodos de pesquisa. Porto Alegre: Editora da UFRGS, 2009.

GEWEHR, D. ET AL. Metodologias ativas de ensino e de aprendizagem: uma abordagem de iniciação à pesquisa. Revista Multidisciplinar de Licenciatura e Formação Docente, v.14, n.01, 2016.

HOSAL-AKMAN, N.; SIMGA-MUGAN, C. An assessment of the effects of teaching methods on academic performance of students in accounting courses. Innovations in Education and Teaching International, v. 47, n. 3, 2010.

KRUGER, L. M; ENSSLIN, S. R. Método tradicional e método construtivista de ensino no processo de aprendizagem. Organizações em contexto. São Bernardo do Campo, v. 9, n. 18, 2013.

KURI, N. P.; SILVA, A. N. R.; PEREIRA, M. A. Estilos de aprendizagem e recursos da hipermídia aplicados no ensino de planejamento de transportes. Revista Portuguesa de Educação. Braga, v. 19, n. 2, p. 111-137, 2006.

LEAL, E. A; BORGES, M. P. P. Estratégias de ensino aplicadas na área da contabilidade gerencial: Um Estudo com discentes do curso de Ciências Contábeis, v. 8 n. 2, 2016.

LIMA T. B; MACEDO N. M. M. N.; SAEGER M. M. M. T. Estudos em Organização e Sociedade. In.: LIMA, T. B. ET AL. João Pessoa/PB: Sal da Terra, 2019.

LIMA, T. B. Fatores facilitadores e limitantes da aprendizagem autodirecionada para o ensino em administração. Revista Gestão.Org, v.14, n. 1, p.125-135, 2016.

LIMA, T. B; SILVA, A. B. Como os mestrandos aprendem? Significados e transformações em um programa de pós-graduação em administração. REUNIR. Revista de Administração, Ciências Contábeis e Sustentabilidade, v.8, n. 1, 2017.

LIMA, T. B; SILVA, A. B. Difusão das perspectivas teóricas da aprendizagem na formação de administradores. REICE - Revista Iberoamericana sobre Calidad, Eficacia y Cambio en Educación, 11 (3), 5-30, 2012.

MADUREIRA, N. L.; SUCCAR F. J.; GOMES, J. S. Estudo sobre os métodos de ensino utilizados nos cursos de ciências contábeis e administração da universidade estadual do Rio de Janeiro (UERJ): a percepção de docentes e discentes. Revista de Informação Contábil, Rio de Janeiro, v. 5, n. 2, p. 43-53, 2011. 
MARQUES, L; BIAVATTI, V. T., Estratégias aplicadas no ensino da contabilidade: evidências dos planos de ensino de uma universidade pública. GUAL - Gestão Universitária da América Latina. v.12, n.2, p. 28, maio, 2019.

MAZZIONI, S. As estratégias utilizadas no processo de ensino-aprendizagem: concepções de alunos e professores de ciências contábeis. Revista Eletrônica de Administração e Turismo, v.2, n. 1, 2013.

MORAN, J. M. Mudando a educação com metodologias ativas. Coleção Mídias Contemporâneas. Convergências midiáticas, educação e cidadania: aproximações jovens, v. 2, Ponta Grossa, 2015.

MOREIRA, M. A. Teorias de aprendizagem. 2. ed. São Paulo: EPU, 2011.

OPDECAM, E.; EVERAERT, P. Improving student satisfaction in a first-year undergraduate accounting course by team learning. Issues in Accounting Education, v. 27, n. 1, 2012.

PAIVA, M. R. F. ET AL. Metodologias ativas de ensino-aprendizagem: revisão integrativa. SANARE. Sobral, v. 15, n. 2, 2016.

PEREIRA, R. Método Ativo: Técnicas de Problematização da Realidade aplicada à Educação Básica e ao Ensino Superior. VI Colóquio Internacional Educação e Contemporaneidade. São Cristóvão/SE, 2012.

PEREIRA, E. M.; NIYAMA, J. K.; FREIRE, F. S. Convergência das Normas Internacionais de Contabilidade: Uma análise a luz das teorias da educação de Paulo Freire e Libaneo nas instituições de ensino do Distrito Federal. In.: CONGRESSO USP DE CONTROLADORIA E CONTABILIDADE, 12, São Paulo, 26 e 27 de julho, 2012. Anais...outubro, 2012.

PINHO, S. T.; ALVES, D. M.; GRECO, P. J.; SCHILD, J. F. G. Método situacional e sua influência no conhecimento tático processual de escolares. Motriz: Revista de Educação Física. Rio Claro, v. 16, n. 3, p. 580-590, jul./set, 2010.

ROMANOWSKY, L. R. E; BEUREN, I. M. Um estudo dos procedimentos metodológicos de ensino utilizados nos cursos de Ciências Contábeis. Revista Brasileira de Contabilidade. Brasília, n. 137, set./out, 2002.

SILVA, T. B. J.; BIAVATTI, V. T. Estratégia metacognitiva de aprendizagem autorregulada, percepção docente sobre a aprendizagem e métodos educacionais em contabilidade. Revista Contemporânea de Contabilidade v. 15, n. 37, p. 03-33, 2019.

SILVA, A. B. ET AL. Dimensões de um sistema de aprendizagem em ação para o ensino de administração. Administração: Ensino \& Pesquisa, v. 13, n. 1, 2012

SIQUEIRA, B. R. Os anéis da serpente: a aprendizagem baseada em problemas e as sociedades de controle. Ciências \& Saúde Coletiva, 2009. 
SOUZA, K. R.; KERBAUY, M. T. M. Abordagem quanti-qualitativa: superação da dicotomia quantitativa-qualitativa na pesquisa em educação. Educação e Filosofia, v. 31, n. 61, p. 2144, abr., 2017.

SPENCER, K. Approaches to Learning and Contemporary Accounting Education. Education in a Changing Environment. Conference Proceedings, 2003.

TRAVERSINI, C. S.; BUAES, C. S. Como discursos dominantes nos espaços da educação atravessam práticas docentes? Revista Portuguesa de Educação. Braga, v. 22, n. 2, p. 141$158,2009$. 